\title{
印加磁場が流れ場中にある強磁性棒状粒子の 配向分布に及ぼす影響*
}

\author{
渡 辺 知 規*1

\section{Orientational Distributions of Ferromagnetic Spherocylinder Particles Influenced by External Magnetic Field}

\author{
Tomonori WATANABE*2 \\ ${ }^{* 2}$ Graduate School of Science \& Technology, Chiba University, \\ 1-33 Yayoi-cho, Inage-ku, Chiba-shi, Chiba, 263-8522 Japan
}

\begin{abstract}
We have analyzed the time-dependent behaviors of the orientational distributions of a dilute colloidal dispersion composed of the ferromagnetic spherocylinder particles influenced by the external magnetic field. A basic equation is derived for the orientational distributions of the particles in steady two dimensional flow by using the perturbation expansion method. An exact solution of the basic equation is obtained theoretically by considering the inverse matrix composed of the functions for the solvable condition. By using the solution, the relevant statistical quantities for an ensemble of the particles are calculated. It is shown that the steady flow causes a distortion of the orientational distribution and can not bring about the steady state of the distribution without the external magnetic field. However, we find the external magnetic field can not always create the steady state of the distribution. We have derived the condition that the steady state of the distribution is made by the external magnetic field and the steady flow. In order to estimate the response of the particles for the magnetic field, the reference time is obtained from the rate of the convergence to the steady state.
\end{abstract}

Key Words : Diffusion, Magnetic Fluid, Cluster, Ferromagnetic Colloidal Dispersion, Spherocylinder, Orientational Distribution Function, Exact Solution

\section{1. 緒言}

知能材料としての利用を目的として, 強磁性コロイ ド分散系に関する研究が活発に行われている(1)(2). 強 磁性コロイド分散系とは，強磁性微粒子を母液に懸濁 しコロイド状態とすることによって，印加した外部磁 場に応答し, 機能性を発揮する磁性流体がなす系のこ とである. この系の主な特徴は, 外部磁場の下で粒子 が凝集して巨大クラスターを形成することである(1) (3). この巨大クラスターは, 流れ場中では大きな抵抗とな り, 見かけの粘度の著しい増加をもたらす. 流体工学 の分野では, この外部磁場による粘度增加の特徽を応 用し, 粘度の制御が可能なダンパーの開発をはじめ, さまざまな工学的応用の試みがなされている(1)(2).

強磁性コロイド分散系の解析には, 現在, 分子動力 学法をはじめとする種々の計算力学的手法が応用され, コロイド粒子の力学的挙動や凝集構造発生のメカニズ

* 原稿受付 2006 年 9 月 26 日.

*1 正員, 千葉大学大学院自然科学研究科(耊 263-8522 千葉市 稲毛区弥生町 1-33)

E-mail : nabe@meneth.tm.chiba-u.ac.jp
ムについて次第に明らかになりつつある(3). 最近では, 一端に正，他端に負の磁荷をもつ棒状のコロイド粒子 を単純せん断流中に分散させた系に対し，定常状態で の特性が詳しく調べられ, 外部から印加した磁場が, コロイド粒子の配向分布とレオロジー特性に及ぼす影 響が定性的に明らかにされている( ${ }^{(4) \sim(7)}$.これらの研究 をふまえ, 強磁性コロイド分散系の工学的応用として, 磁場による粒子の配向制御を行うためには, 磁場に対 する応答性として，系の時間挙動を明らかにし，さら に，磁場と流机場が配向分布にもたらす影響を定量的 に評価する必要がある，そこで，本研究では，強磁性 棒状粒子からなるコロイド分散系での粒子の配向分布 に磁場が及ぼす影響を時間を含めて解析的に明らかに することを目的とする.

これまで，Kim らは，軸対称粒子についての配 向挙動を明らかにするために, TPA（Tangent Plane Approximation）を用いた配向分布が満たす相似解の 導出を試みている ${ }^{(8)}$. しかし, 相似解を導出する際の 条件式が非線形の微分方程式系になるために, Kim ら の解析結果は, 定常状態と微小時間挙動に限られたも 
のになっている．また，磁場の方向についても二次元 流れ場がなす平面に垂直な方向に限定している.

本研究では，まず，支配方程式に対し，適切な変数 変換と摂動展開を用いることにより, 本研究での基礎 方程式を導出する．この方程式の厳密解を得るために は, Kim らが相似解を導出する際に得た非線形の微分 方程式系と同等の方程式系を解く必要がある. そこで, 本研究では，条件式から導かれる行列の逆行列に着目 することにより, 可解条件としての微分方程式系を解 き, 基礎方程式の厳密解を導出する. これにより, 解 析的に, 配向分布の特徵と時間挙動について定量的な 評価を行う. また, 磁場方向としては, 二次元流れ場 がなす平面に垂直な方向が支配的な条件のもと，任意 の磁場方向に対して解析を行う.

\section{2. 支配方程 式}

母液に懸濁された強磁性棒状粒子のモデルには，こ れまでの研究 ${ }^{(4) \sim(7)}$ と同様に, 自由な回転が可能な, 円 柱の両端が半球状の形状を有する spherocylinder（球 冠円柱）モデルを用いる（図 1）。モデルでは，円柱 部の長さを $l$, 直径を $d$ とし, 粒子のアスペクト比 $r_{\mathrm{p}}$ を， $r_{\mathrm{p}} \equiv l / d$ とする. また，磁荷 $\pm q$ は，それぞれの 半球を形づくる球の中心点にあるものとする.このよ うな棒状粒子は，球状粒子に比べ大きな磁気粘性効果 が得られると期待され, 活発に研究が行われている ${ }^{(9)}$. 特に，近年では，粒子の大きさや磁気的性質を精密に 制御した粒子の生成法が提案され，さまざまな大きさ をもつ粒子の生成が可能になつている ${ }^{(9)}$. 本研究では, 粒子の長さのオーダーについては，典型的なものを想 定し, $10^{-7} \mathrm{~m}$ 程度とする.

本研究では, 希釈系の取り扱いについては, 従来の 研究 ${ }^{(4)(5)}$ に従い，希釈系を，コロイド粒子が，粒子同 土のクーロン相互作用を無視できる程度に分散してい る系として定義し, 粒子に作用するトルクには, 粒子 間相互作用に起因するトルクは考慮せず, 印加磁場に 起因する磁気力によるトルク $T^{\mathrm{m}}$, 回転ブラウン運動 によるトルク $T^{\mathrm{Br}}$, および, せん断流に起因して流体 が粒子に作用するトルク $\boldsymbol{T}^{\mathrm{fl}}$ のみを考慮するものとす る. よって, 流れ場中における粒子の回転運動は, コ ロイド粒子の場合, 慣性項は無視できるオーダーなの で, 以下のトルクのつりあい方程式によって得ること ができる(4).

ただし，各項は，

$$
\mathbf{0}=\boldsymbol{T}^{\mathrm{m}}+\boldsymbol{T}^{\mathrm{Br}}+\boldsymbol{T}^{\mathrm{fl}} .
$$

$$
\begin{aligned}
\boldsymbol{T}^{\mathrm{m}} & =\mu_{0} \boldsymbol{m} \times \boldsymbol{H}, \\
\boldsymbol{T}^{\mathrm{Br}} & =-k_{\mathrm{B}} T \boldsymbol{e} \times \frac{\partial}{\partial \boldsymbol{e}} \ln \Psi,
\end{aligned}
$$

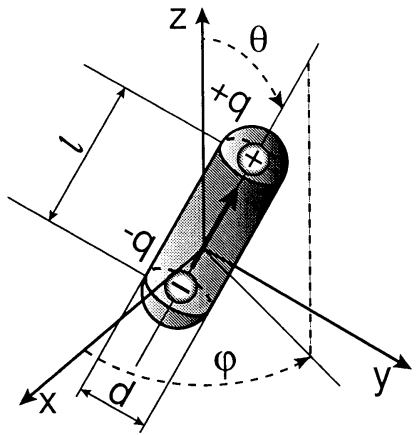

Fig. 1 Particle model and coordinate system.

$$
\begin{gathered}
\boldsymbol{T}^{\mathrm{fl}}=\eta_{\mathrm{s}}\left\{X^{\mathrm{C}} \boldsymbol{e} \boldsymbol{e}+Y^{\mathrm{C}}(\boldsymbol{I}-\boldsymbol{e} \boldsymbol{e})\right\} \cdot(\boldsymbol{\Omega}-\boldsymbol{\omega}) \\
-\eta_{\mathrm{s}} Y^{\mathrm{H}}(\boldsymbol{\epsilon} \cdot \boldsymbol{e} \boldsymbol{e}): \boldsymbol{E},
\end{gathered}
$$

であり, 式中の各記号は以下で与えられる(4)(10) $\cdot \mu_{0}$ は, 真空の透磁率であり, 磁気モーメント: $\boldsymbol{m}(m=|\boldsymbol{m}|)$ は, $\boldsymbol{m} \equiv q l e$ で定義される量である. $k_{\mathrm{B}}$ はボルツマン定数, $T$ は系の温度， $\Psi$ は粒子の配向分布関数である.また, $\boldsymbol{\Omega}$ と $\boldsymbol{E}$ は，流れ場の回転角速度べクトルと変形速度テ ンソル， $\omega$ は粒子の角速度ベクトルである.さらに， $\eta_{\mathrm{s}}$ は母液の粘度, $\epsilon$ は 3 階のテンソルであるエディン トンのイプシロン, I は単位テンソルである. $X^{\mathrm{C}}, Y^{\mathrm{C}}$ および $Y^{\mathrm{H}}$ は，抵抗関数で粒子の幾何学的形状のみに 依存する量である(11). また, $\boldsymbol{H}(H=|\boldsymbol{H}|, \boldsymbol{h} \equiv \boldsymbol{H} / H)$ は, 外部から印加される磁場である。

一方, 粒子の配向分布関数 $\Psi$ は, 保存則, すなわ ち, 連続の式 :

$$
\frac{\partial \Psi}{\partial t}=-\frac{\partial}{\partial \boldsymbol{e}} \cdot(\dot{\boldsymbol{e}} \Psi),
$$

を満たす(4). そこで, トルクのつりあい方程式 (1) か ら得られる $\dot{e}$ を代入し, 整理すると配向分布関数が満 たす方程式として,

$$
\begin{aligned}
\frac{\partial \Psi}{\partial t} & =3 \rho(\boldsymbol{E}: \boldsymbol{e} \boldsymbol{e}) \Psi-\{\boldsymbol{\Omega} \times \boldsymbol{e}+\rho(\boldsymbol{E} \cdot \boldsymbol{e})\} \cdot \frac{\partial \Psi}{\partial \boldsymbol{e}} \\
& +D_{\mathrm{r}}\left(\frac{\partial}{\partial \boldsymbol{e}} \cdot \frac{\partial}{\partial \boldsymbol{e}}\right) \Psi+\frac{\mu_{0} m H}{\eta_{\mathrm{s}} Y^{\mathrm{C}}}\left\{2(\boldsymbol{e} \cdot \boldsymbol{h}) \Psi-\boldsymbol{h} \cdot \frac{\partial \Psi}{\partial \boldsymbol{e}}\right\},
\end{aligned}
$$

を得ることができる，ただし，ここで，回転拡散係数 $D_{\mathrm{r}}$ を $D_{\mathrm{r}} \equiv k_{\mathrm{B}} T /\left(\eta_{\mathrm{s}} Y^{\mathrm{C}}\right)$ ，また， $\rho \equiv Y^{\mathrm{H}} / Y^{\mathrm{C}}$ とした.

本研究では, 系の基本的特性を解析的に調べること が目的であるので, 流れ場については, コロイド粒子 が単純せん断流中にある場合についてのこれまでの研 究結果 ${ }^{(4) \sim(7)}$ との対比を考慮し, 二次元流れ場とする. また，磁場については，対称性による系の取り扱い易 さから, 磁場方向として, 二次元流れ場がなす平面に 垂直な方向が支配的であるとした場合での，任意の磁 場方向に対して解析を行うことにする. 具体的には, 
直交座標系の基本ベクトルを $\left(\delta_{\mathrm{x}}, \delta_{\mathrm{y}}, \delta_{z}\right)$ とすると，粒 子が存在する前の二次元流㧈場の流速 $U \equiv u \delta_{\mathrm{x}}+v \delta_{\mathrm{y}}$, 回転角速度ベクトル $\boldsymbol{\Omega}$ および変形速度テンソル $\boldsymbol{E}$ を,

$$
\begin{aligned}
& \left(\begin{array}{l}
u \\
v
\end{array}\right)=\dot{\gamma}\left(\begin{array}{cc}
E_{11} & E_{12}-G_{3} \\
E_{12}+G_{3} & E_{22}
\end{array}\right)\left(\begin{array}{l}
x \\
y
\end{array}\right), \\
& \boldsymbol{\Omega}=\dot{\gamma}\left(\begin{array}{c}
0 \\
0 \\
G_{3}
\end{array}\right), \quad \boldsymbol{E}=\dot{\gamma}\left(\begin{array}{ccc}
E_{11} & E_{12} & 0 \\
E_{12} & E_{22} & 0 \\
0 & 0 & 0
\end{array}\right),
\end{aligned}
$$

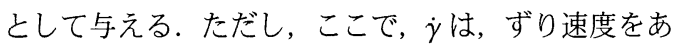
らわすものとし, $-1 \leq G_{3} \leq 1$, および, $\operatorname{Tr}(\boldsymbol{E})=0$ とす る. また, 磁場 $\boldsymbol{h}$ については, 一般的な表式として, $\boldsymbol{h} \equiv h_{\mathrm{x}} \boldsymbol{\delta}_{\mathrm{x}}+h_{\mathrm{y}} \boldsymbol{\delta}_{\mathrm{y}}+h_{\mathrm{z}} \boldsymbol{\delta}_{\mathrm{z}},\left(h_{\mathrm{x}}^{2}+h_{\mathrm{y}}^{2}+h_{\mathrm{z}}^{2}=1\right)$ と書くことに する（ただし，各成分間の関係については，次章の 式 (24) で定める).

以上の条件を式 (6) に代入すると, 配向分布関数 $\Psi$ が満たす方程式として,

$$
\begin{aligned}
\frac{1}{\dot{\gamma}} \frac{\partial \Psi}{\partial t}=\frac{1}{P_{\mathrm{e}}} & \Lambda(\Psi)-\Omega_{\mathrm{s}}(\Psi)+\frac{1}{P_{\mathrm{e}}}\left(\xi h_{\mathrm{x}}\right) \Omega_{\mathrm{mx}}(\Psi) \\
& +\frac{1}{P_{\mathrm{e}}}\left(\xi h_{\mathrm{y}}\right) \Omega_{\mathrm{my}}(\Psi)+\frac{1}{P_{\mathrm{e}}}\left(\xi h_{\mathrm{z}}\right) \Omega_{\mathrm{mz}}(\Psi),
\end{aligned}
$$

を得ることができる.この方程式が, 本研究での支配 方程式になる．ただし，ここで，各項と記号は，

であり

$$
\begin{aligned}
& \Lambda(\Psi):=\frac{1}{S} \frac{\partial}{\partial \theta}\left(S \frac{\partial \Psi}{\partial \theta}\right)+\frac{1}{S^{2}} \frac{\partial^{2} \Psi}{\partial \varphi^{2}}, \\
& \Omega_{\mathrm{mx}}(\Psi):=2 S c \Psi-C c \frac{\partial \Psi}{\partial \theta}+\frac{s}{S} \frac{\partial \Psi}{\partial \varphi}, \\
& \Omega_{\mathrm{my}}(\Psi):=2 S s \Psi-C s \frac{\partial \Psi}{\partial \theta}-\frac{c}{S} \frac{\partial \Psi}{\partial \varphi}, \\
& \Omega_{\mathrm{mz}}(\Psi):=2 C \Psi+S \frac{\partial \Psi}{\partial \theta}
\end{aligned}
$$

$$
\begin{aligned}
& \Omega_{\mathrm{S}}(\Psi):=\rho E_{12} \Omega_{E 12}+\rho E_{11} \Omega_{E 11}+\rho E_{22} \Omega_{E 22}+G_{3} \Omega_{G 3}, \\
& \Omega_{E 12}:=\frac{2 s c}{S} \frac{\partial}{\partial \theta}\left(S^{2} C \Psi\right)-2 \frac{\partial}{\partial \varphi}\left(s^{2} \Psi\right)+\frac{\partial}{\partial \varphi} \Psi, \\
& \Omega_{E 11}:=\frac{c^{2}}{S} \frac{\partial}{\partial \theta}\left(S^{2} C \Psi\right)-\frac{\partial}{\partial \varphi}(s c \Psi), \\
& \Omega_{E 22}:=\frac{s^{2}}{S} \frac{\partial}{\partial \theta}\left(S^{2} C \Psi\right)+\frac{\partial}{\partial \varphi}(s c \Psi), \\
& \Omega_{G 3}:=\frac{\partial}{\partial \varphi} \Psi,
\end{aligned}
$$

および, $S \equiv \sin \theta, C \equiv \cos \theta, s \equiv \sin \varphi, c \equiv \cos \varphi$ を意味 する. また, $P_{\mathrm{e}}$ は, ペクレ数と呼ばれ, 回転ブラウン 運動に対するせん断流の影響の大きさを表し $P_{\mathrm{e}} \equiv \dot{\gamma} / D_{\mathrm{r}}$ で与えられる. $\xi$ は, 回転ブラウン運動に対する磁場 の影響の大きさを表し， $\xi \equiv \mu_{0} m H /\left(k_{\mathrm{B}} T\right)$ で与えられ る. また, 対象が棒状粒子であるので, アスペクト比 を $r_{\mathrm{p}} \gg 1$ とし, 以下では $\rho\left(=Y^{\mathrm{H}} / Y^{\mathrm{C}}\right) \approx 1$ とする.

\section{3. 摂動展開の方法}

本研究では, 支配方程式 (9) を, 変数変換と摂動展開 の方法を用いて直接的に解析することを試みる. 摂動 展開にあたっては, 各項のバランスを適切にみきわめ ることが重要な問題となる. そのため, 適切な変数変 換と摂動展開を定めることが必要となる. 本研究では, 以下に示す変数変換と摂動パラメー夕 $\varepsilon$ を用いた摂動 展開を行う.この変換と展開の妥当性については, 後 の考察にて検討を行う. まず, 変数変換 $(\theta, \varphi) \rightarrow(x, y)$;

$$
\begin{array}{ll}
\sin \theta=\sqrt{x^{2}+y^{2}}, & \cos \theta=\sqrt{1-x^{2}-y^{2}}, \\
\sin \varphi=\frac{y}{\sqrt{x^{2}+y^{2}}}, & \cos \varphi=\frac{x}{\sqrt{x^{2}+y^{2}}},
\end{array}
$$

を行う.つぎに, 摂動展開として,

$$
\begin{aligned}
& x=\varepsilon \tilde{x}, \quad y=\varepsilon \tilde{y}, \quad t=\dot{\gamma}^{-1} \tilde{t}, \\
& \Psi(x, y, t)=\Psi^{(0)}(\tilde{x}, \tilde{y}, t)+\varepsilon \Psi^{(1)}(\tilde{x}, \tilde{y}, t)+\cdots, \\
& P_{\mathrm{e}}=\varepsilon^{-2} \tilde{P}_{\mathrm{e}}, \quad \xi=\varepsilon^{-2} \tilde{\xi}, \\
& h_{\mathrm{x}}=\varepsilon \tilde{h}_{\mathrm{x}}, \quad h_{\mathrm{y}}=\varepsilon \tilde{h}_{\mathrm{y}}, \quad h_{\mathrm{z}}=\sqrt{1-\left(h_{\mathrm{x}}^{2}+h_{\mathrm{y}}^{2}\right)},
\end{aligned}
$$

を行う. ただし, ここでは, 変換後の変数には, チル ダをつけて表しているが, 以後の式では, 便宜上, チ ルダをとって表記するものとする. このような変数変 換と摂動展開を行うと, 摂動パラメータ $\varepsilon$ の最低次数 の式として,

$$
\begin{aligned}
& \Psi_{t}^{(0)}=\frac{1}{P}\left(\Psi_{x x}^{(0)}+\right.\left.\Psi_{y y}^{(0)}\right)+(1-\beta) M\left(x-\mu_{\mathrm{x}}\right) \Psi_{x}^{(0)} \\
&+\tilde{G}\left(y-\mu_{\mathrm{y}}\right) \Psi_{x}^{(0)}+\alpha \tilde{G}\left(x-\mu_{\mathrm{x}}\right) \Psi_{y}^{(0)} \\
&+(1+\beta) M\left(y-\mu_{\mathrm{y}}\right) \Psi_{y}^{(0)}+2 M \Psi^{(0)},
\end{aligned}
$$

を得ることができる. ただし，式中の， $\tilde{G}, \alpha, \beta, M$, $\mu_{\mathrm{x}}$, および, $\mu_{\mathrm{y}}$ は以下によって与えるものとする.

$$
\begin{aligned}
\tilde{G} & :=G_{3}-E_{12}, \alpha:=-\left(G_{3}+E_{12}\right) /\left(G_{3}-E_{12}\right), \\
M & :=\xi / P_{\mathrm{e}}, \quad \beta:=E_{11} /\left(\xi / P_{\mathrm{e}}\right), \\
\mu_{\mathrm{x}} & :=\frac{\xi\left\{\left(E_{12}-G_{3}\right) h_{\mathrm{y}} P_{\mathrm{e}}+h_{\mathrm{x}}\left(\xi+E_{11} P_{\mathrm{e}}\right)\right\}}{\xi^{2}-\left(E_{11}{ }^{2}+E_{12}{ }^{2}-G_{3}{ }^{2}\right) P_{\mathrm{e}}^{2}}, \\
\mu_{\mathrm{y}} & :=\frac{\xi\left\{\left(E_{12}+G_{3}\right) h_{\mathrm{x}} P_{\mathrm{e}}+h_{\mathrm{y}}\left(\xi-E_{11} P_{\mathrm{e}}\right)\right\}}{\xi^{2}-\left(E_{11}^{2}+E_{12}{ }^{2}-G_{3}^{2}\right) P_{\mathrm{e}}^{2}} .
\end{aligned}
$$

以上のようにして得た式 (25) が本研究での基礎方程 式である. 次章では, 式 (25) の厳密解を導出する.

\section{4. 方程式の 解}

これまで, 単純せん断流下での定常状態においては, ガラーキン法を応用した数值解析によって, ひとつの ピークをもち, 遠方では, 零となる配向分布が存在す ることが知られている(4) (7). このことを考虑し, 方程 式 (25)に対して，規格化をした解を定めると， 


$$
\begin{gathered}
\Psi^{(0)}(x, y, t)=\frac{\sqrt{B_{\mathrm{xx}} B_{\mathrm{yy}}-B_{\mathrm{xy}}{ }^{2}}}{2 \pi} \exp \left[-\frac{1}{2}\left\{B_{\mathrm{xx}}(t)\left(x-\mu_{\mathrm{x}}\right)^{2}\right.\right. \\
\left.\left.+2 B_{\mathrm{xy}}(t)\left(x-\mu_{\mathrm{x}}\right)\left(y-\mu_{\mathrm{y}}\right)+B_{\mathrm{yy}}(t)\left(y-\mu_{\mathrm{y}}\right)^{2}\right\}\right], \quad
\end{gathered}
$$

を得ることができる．ただし，ここで，時間について の関数 $B_{i j}(t),(i, j=\mathrm{x}, \mathrm{y})$ は, 任意の時間 $t$ に対して,

$$
B_{\mathrm{xx}} \geq 0, \quad B_{\mathrm{yy}} \geq 0, \quad B_{\mathrm{xx}} B_{\mathrm{yy}} \geq B_{\mathrm{xy}}{ }^{2},
$$

を満たすとする. また, 関数 $B_{i j}(t)$ は, 解 (30) が方程 式 (25) を満たすように定まるものとする.この場合, 方程式 (25) の可解条件は, $B_{i j}(t)$ についての非線形連 立方程式系で与えられ，直接解を求めることは，一般 的に非常に難しい。事実，Kim らは，伸張流下におい て TPA を用いて方程式 (25) と同等の式を導出し, 相 似解を求めることを試みているが，条件として得られ る非線形連立方程式系を厳密には解かずに，微小時間 に近似をした解析を行っている ${ }^{(8)}$.

そこで, 本研究では, 方程式 (25) の厳密解を得る ために, 関数 $B_{i j}(t)$ がつくる行列の逆行列に注目する. すなわち, 行列 $B(t)$ と, 逆行列 $B^{-1}(t)$ を,

$$
B(t) \equiv\left(\begin{array}{ll}
B_{\mathrm{xx}}(t) & B_{\mathrm{xy}}(t) \\
B_{\mathrm{xy}}(t) & B_{\mathrm{yy}}(t)
\end{array}\right), B^{-1}(t) \equiv\left(\begin{array}{ll}
B_{\mathrm{xx}}^{-1}(t) & B_{\mathrm{xy}}^{-1}(t) \\
B_{\mathrm{xy}}^{-1}(t) & B_{\mathrm{yy}}^{-1}(t)
\end{array}\right),
$$

とし, 関数 $B_{i j}(t)$ が満たす可解条件としての非線形連 立方程式系に対し， $B^{-1}(t)$ を用いた解析を行う。この 方法を用いると, $B^{-1}(t)$ について厳密に解くことがで きる. 実際に, 初期值を, $B_{\mathrm{xx}}^{-1}(0)=0, B_{\mathrm{xy}}^{-1}(0)=0$ およ び $B_{\mathrm{yy}}^{-1}(0)=0$ としたときの特解と行列式 $\operatorname{det} B^{-1}$ を以 下に示す。

$$
\begin{gathered}
B_{\mathrm{xx}}^{-1}(t)=\frac{\left(1 / P_{\mathrm{e}}\right)}{2 A M\left(M^{2}-A\right)}\left[A\left\{2 M^{2}(1+\beta)+(1-\alpha) \tilde{G}^{2}\right\}\right. \\
-e^{-2 M t} M^{2}\left\{2 A(1+\beta)+(1-\alpha) \tilde{G}^{2}\right\} \cosh (2 \sqrt{A} t) \\
-\sqrt{A} e^{-2 M t} M\left\{(1+\alpha) \tilde{G}^{2}+2 \beta(1+\beta) M^{2}\right\} \sinh (2 \sqrt{A} t) \\
\left.+(1-\alpha) \tilde{G}^{2}\left(M^{2}-A\right) e^{-2 M t}\right], \quad(33) \\
B_{\mathrm{xy}}^{-1}(t)=\frac{\left(\tilde{G} / P_{\mathrm{e}}\right)}{2 A\left(M^{2}-A\right)}[A\{\beta(1-\alpha)-(1+\alpha)\} \\
+e^{-2 M t}\left\{A(1+\alpha)-(1-\alpha) \beta M^{2}\right\} \cosh (2 \sqrt{A} t) \\
-\sqrt{A}\{\beta(1-\alpha)-(1+\alpha)\} e^{-2 M t} M \sinh (2 \sqrt{A} t) \\
\left.+\beta(1-\alpha)\left(M^{2}-A\right) e^{-2 M t}\right], \quad(34) \\
B_{\mathrm{yy}}^{-1}(t)=\frac{\left(1 / P_{\mathrm{e}}\right)}{2 A M\left(M^{2}-A\right)}\left[A\left\{2 M^{2}(1-\beta)-\alpha(1-\alpha) \tilde{G}^{2}\right\}\right. \\
-e^{-2 M t} M^{2}\left\{2 A(1-\beta)-\alpha(1-\alpha) \tilde{G}^{2}\right\} \cosh (2 \sqrt{A} t) \\
-\sqrt{A} e^{-2 M t} M\left\{\alpha(1+\alpha) \tilde{G}^{2}-2 \beta(1-\beta) M^{2}\right\} \sinh (2 \sqrt{A} t) \\
\left.-\alpha(1-\alpha) \tilde{G}^{2}\left(M^{2}-A\right) e^{-2 M t}\right], \quad(35)
\end{gathered}
$$

$$
\begin{gathered}
\operatorname{det} B^{-1}(t)=\frac{\left(1 / P_{\mathrm{e}}\right)^{2}}{4 A M^{2}\left(M^{2}-A\right)}\left[2(1-\alpha)^{2} e^{-2 M t} \tilde{G}^{2} M^{2}\right. \\
+A\left\{(1-\alpha)^{2}\left(1-e^{-2 M t}\right)^{2} \tilde{G}^{2}+4\left(1+e^{-4 M t}\right) M^{2}\right\} \\
\left.-2 e^{-2 M t} M^{2}\left\{4 A+(1-\alpha)^{2} \tilde{G}^{2}\right\} \cosh (2 \sqrt{A} t)\right] .
\end{gathered}
$$

ただし、ここで, $A$ は, $A:=\beta^{2} M^{2}+\alpha \tilde{G}^{2}$ とした. よっ $\tau$, この逆行列 $B^{-1}(t)$ と, $\operatorname{det} B(t) \cdot \operatorname{det} B^{-1}(t)=1$ など の関係式を用いると, 厳密解として, 解 (30) をあらわ に得ることができる. 事実, 解 (30) が上記の $B_{i j}^{-1}(t)$ の もとで, 方程式 (25) を満たすことは, 代入をして確か めることができる.

厳密解 (30) を用いると, さまざまな統計平均量を計 算することができる. 実際に, 配向分布関数 $\Psi^{(0)}$ を用 いた統計平均を,

$$
\langle 1\rangle^{(0)}:=\int_{-\infty}^{\infty} \mathrm{d} x \int_{-\infty}^{\infty} \mathrm{d} y 1 \cdot \Psi^{(0)}(t, x, y)=1,
$$

とし，代表的なものを計算すると，

$$
\begin{gathered}
\langle x\rangle^{(0)}=\mu_{\mathrm{x}}, \quad\langle y\rangle^{(0)}=\mu_{\mathrm{y}}, \\
\left\langle x^{2}\right\rangle^{(0)}=\mu_{\mathrm{x}}^{2}+B_{\mathrm{xx}}^{-1}(t), \\
\langle x y\rangle^{(0)}=\mu_{\mathrm{x}} \mu_{\mathrm{y}}+B_{\mathrm{xy}}^{-1}(t), \\
\left\langle y^{2}\right\rangle^{(0)}=\mu_{\mathrm{y}}^{2}+B_{\mathrm{yy}}^{-1}(t),
\end{gathered}
$$

となる.これらの量の特徵については, 次章にて考察 を行う.

\section{5. 結果と考察}

\section{1 流れ場が粒子の配向分布に及ぼす影響 考} 察を行うにあたり，まず，配向分布の基本的特徵をお さえるために, 磁場の影響が無い場合 $(\xi \rightarrow 0)$ につ いて考察を行う.つぎに，磁場を含めた分布について の議論を行うことにする. また, 配向分布のピークの 位置 $\left(\mu_{\mathrm{x}}, \mu_{\mathrm{y}}\right)$ は, 分布形状には影響を及ぼさないので, 便宜上, $\left(\mu_{\mathrm{x}}, \mu_{\mathrm{y}}\right)=(0,0)$ とする. 以上のことをふまえ， まず, 流れ場として, 回転角速度べクトル $\boldsymbol{\Omega}$ と変形 速度テンソル $\boldsymbol{E}$ が粒子の配向分布に及ぼす影響につ いて考察を行う. 流れ場が分布におよぼす影響は, 方 程式 (25) を見ると, 方程式の係数 $\left(\alpha, \tilde{G}\right.$ および $\left.E_{11}\right)$ を通して現れていることがわかる，そこで，方程式の 係数の代表的な例 ${ }^{(12)}$ として, 以下の 5 つの場合 :

1. $E_{11}=0, G_{3}=\tilde{G}, E_{12}=0,(\alpha=-1)$.

2. $E_{11}=0, G_{3}=\tilde{G} / 2, E_{12}=-\tilde{G} / 2,(\alpha=0)$.

3. $E_{11}=0, G_{3}=0, E_{12}=-\tilde{G},(\alpha=1)$.

4. $E_{11}=0, G_{3}=E_{12}$.

5. $G_{3}=0, E_{12}=0$.

について考える.すすおち，方程式の係数（ $\alpha ， \tilde{G}$ お よび $\left.E_{11}\right)$ のうち, 場合 1 から 4 までは, $E_{11}=0$ とし 
Table 1 Statistical quantities for the case 1 to $5 . \quad \operatorname{Sh}(x):=\sinh \left(2 \sqrt{x^{2}} \dot{\gamma} t\right), \quad C h(x):=\cosh \left(2 \sqrt{x^{2}} \dot{\gamma} t\right)$.

\begin{tabular}{c||c|c|c}
\hline & $\left\langle x^{2}\right\rangle^{(0)}$ & $\langle x y\rangle^{(0)}$ & $\left\langle y^{2}\right\rangle^{(0)}$ \\
\hline 1 & $2 P_{\mathrm{e}}^{-1} \dot{\gamma} t=2 D_{\mathrm{r}} t$ & 0 & $2 P_{\mathrm{e}}^{-1} \dot{\gamma} t=2 D_{\mathrm{r}} t$ \\
2 & $(2 \dot{\gamma} t)\left(3 P_{\mathrm{e}}\right)^{-1}\left(3+4 E_{12}{ }^{2}(\dot{\gamma} t)^{2}\right)$ & $2 P_{\mathrm{e}}^{-1} E_{12}(\dot{\gamma} t)^{2}$ & $2 P_{\mathrm{e}}^{-1} \dot{\gamma} t=2 D_{\mathrm{r}} t$ \\
3 & $S h\left(E_{12}\right)\left(P_{\mathrm{e}} \sqrt{E_{12}}\right)^{-1}$ & $\left(C h\left(E_{12}\right)-1\right)\left(P_{\mathrm{e}} E_{12}\right)^{-1}$ & $S h\left(E_{12}\right)\left(P_{\mathrm{e}} \sqrt{E_{12}}\right)^{-1}$ \\
4 & $2 P_{\mathrm{e}}^{-1} \dot{\gamma} t=2 D_{\mathrm{r}} t$ & $2 P_{\mathrm{e}}^{-1} E_{12}(\dot{\gamma} t)^{2}$ & $(2 \dot{\gamma} t)\left(3 P_{\mathrm{e}}\right)^{-1}\left(3+4 E_{12}{ }^{2}(\dot{\gamma} t)^{2}\right)$ \\
5 & 0 & $\left(E_{11}-E_{11} C h\left(E_{11}\right)+\sqrt{E_{11}{ }^{2}} \operatorname{Sh}\left(E_{11}\right)\right)$ \\
& $\left(-E_{11}+E_{11} C h\left(E_{11}\right)+\sqrt{E_{11}{ }^{2}} \operatorname{Sh}\left(E_{11}\right)\right)$ & & $\times\left(P_{\mathrm{e}} E_{11}\right)^{-1}$ \\
\hline
\end{tabular}

て， $\alpha$ と $\tilde{G}$ を変化させた場合であり, 場合 5 は, $\tilde{G}=0$ $(\alpha=0)$ として, $E_{11}$ を与えた場合を意味する.これ らの五つの場合について, 統計平均量を計算した結果 を, 表 1 に示す.

まず, 場合 1 では, $\left\langle x^{2}\right\rangle^{(0)}$ と $\left\langle y^{2}\right\rangle^{(0)}$ のみが値を持ち, ともに同じ值であった.このことから, 場合 1 では, 流れ場は回転的性質を示し, 配向分布は $x$ 方向と $y$ 方 向ともに均等に拡散していくことがわかる. また, 拡 散の程度としては, 二乗平均值が, Brown 運動につい て知られている Einstein の関係式に対応する形になつ ている.このことから, 粒子は, Brown 運動の典型的 な挙動を示すことがわかる.

一方, 場合 2 から 5 については, 表 1 から, 方程式 の係数の違いによって, 分布にゆがみが発生すること がわかる．また，ゆがみの成長の仕方には場合によっ て, 違いがあることもわかる. そこで, 配向分布のゆ がみの特徵を捉えるために, 配向分布関数を極座標表 示し, 動径方向に積分した関数 : $p(\phi, t),(\phi$ は, 極座 標表示をした時の角度），

$p(\phi, t):=\int_{0}^{\infty} r \mathrm{~d} r \Psi^{(0)}(r \cos \phi, r \sin \phi, t)$

$$
=\frac{\sqrt{\operatorname{det} B^{-1}}}{2 \pi\left(\cos ^{2} \phi B_{\mathrm{yy}}^{-1}-2 \sin \phi \cos \phi B_{\mathrm{xy}}^{-1}+B_{\mathrm{xx}}^{-1} \sin ^{2} \phi\right)},
$$

を定義し(12), 考察を行う.

図 2 から 4 に, $p(\phi, t)$ の時間発展の様子を示す. 時 間は，それぞれ， $\dot{\gamma} t=0.5,2,4,20$ とした. 条件として は, 図 2 は, 場合 2 に対応するものとして, 流机場 を $\left(E_{11}, G_{3}, E_{12}\right)=(0,-1 / 2,1 / 2)$, 図 3 は, 場合 3 に対 応するものとして, 流れ場を $\left(E_{11}, G_{3}, E_{12}\right)=(0,0,1)$, 図 4 は, 場合 5 に対応するものとして, 流机場を $\left(E_{11}, G_{3}, E_{12}\right)=(1,0,0)$ とした.

まず，図 2 によると, 配向分布は, 時間の発展とと もに, 徐々にゆがみの方向をかえながら, 最終的には 一方向に成長をしていくことがわかる.このことから， 場合 2 につては, 流机場は, 単純せん断としての性 質を示しており, 分布は, 流れがつくる方向に徐々に
ゆがめられながら拡散していくことがわかる．以上の 特徵は, 場合 4 においても同様に見られた.

つぎに, 図 3 によると, 図 2 の傾向とは異なり, 配 向分布は, はじめから特定の一方向のみが成長をし, その方向から $\pi / 2$ ずれた方向では, 逆に縮んでいくこ とがわかる.このことから, 場合 3 について, 流れ 場は, 純粋せん断としての性質を示しており, 分布は, 流れによって伸張と圧縮をともなって拡散していくこ とがわかる. また, 図 4 では, 図 3 の場合と同様の傾 向をもつことがわかる. よって, 場合 5 では, 流扎場 は, $E_{11}$ によって伸張（圧縮）的性質を示し, 分布は, 流れによって伸張と圧縮をともなって拡散していくこ とがわかる.

以上のことから, 方程式の係数による分類によって 得られた流れ場の特徵は, 回転角速度べクトル $\boldsymbol{\Omega}$ 亡変 形速度テンソル $\boldsymbol{E}$ がもつ本来の意味と合致することが わかる. このことから本研究での解析手法の妥当性を 確認することができる. さらに, 流れ場がもたらす配向 分布のゆがみの特徵として重要なことは, 磁場がはた らかない場合 $(\xi \rightarrow 0)$ では, 配向分布は必ず拡散して しまうということである. 事実, $\lim _{t \rightarrow \infty} \lim _{\xi \rightarrow 0} \operatorname{det} B(t)^{-1}=\infty$ であるので,

$$
\lim _{t \rightarrow \infty} \lim _{\xi \rightarrow 0} \Psi^{(0)}(x, y, t)=0,
$$

となり，必ず分布は拡散する. すなわち,このことは, 流れ場だけでは, 粒子の配向を維持させることは不可 能であり, 配向分布を制御するためには, 磁場が必要 であることを意味している.

5.2 磁場が粒子の配向分布に及ぼす影響 前節 では，流れ場が配向分布に及ぼす影響を調べ，流れ場 だけでは，配向分布は拡散してしまうことを明らかに した．このことから，配向分布を維持するためには， 磁場が必要であることがわかった. では, 逆に, 磁場 が印加されれば, 必ず粒子の配向は維持され, 配向分 布を制御することができるのであろうか?

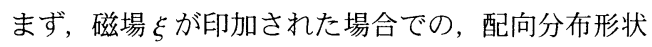
の特徵を明らかにするために, 二次形式の標準形を用 


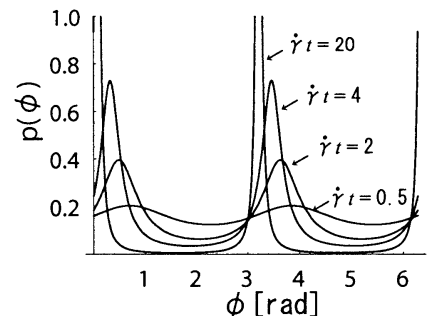

Fig. 2 Polar plots of the probabilities $p(\phi, t)$ for the case $2(\alpha=0)$ under the condition that $E_{11}=$ $0, G_{3}=-1 / 2$ and $E_{12}=1 / 2 . \dot{\gamma} t=0.5,2,4$ and 20.

いて，配向分布関数を以下のように変形する.

$$
\begin{gathered}
\Psi^{(0)}=\frac{P_{\mathrm{e}}}{\pi a(t) b(t)} \exp \left[-P_{\mathrm{e}}\left(\frac{\hat{x}(t)^{2}}{a(t)^{2}}+\frac{\hat{y}(t)^{2}}{b(t)^{2}}\right)\right], \\
\hat{x}(t):=x \cos \psi(t)+y \sin \psi(t), \\
\hat{y}(t):=-x \sin \psi(t)+y \cos \psi(t), \\
Z(t):=\tan \psi(t) .
\end{gathered}
$$

ここで, $a(t), b(t)$, および, $Z(t)$ は,

$$
N(t):=\left(B_{\mathrm{xx}}^{-1}+B_{\mathrm{yy}}^{-1}\right)^{2}-4 \operatorname{det} B^{-1},
$$

とおくと，具体的には，以下となる.

$$
\begin{aligned}
& a(t)=\sqrt{P_{\mathrm{e}}\left(B_{\mathrm{xx}}^{-1}+B_{\mathrm{yy}}^{-1}+\sqrt{N}\right)}, \\
& b(t)=\sqrt{P_{\mathrm{e}}\left(B_{\mathrm{xx}}^{-1}+B_{\mathrm{yy}}^{-1}-\sqrt{N}\right)}, \\
& Z(t)=\frac{-\left(B_{\mathrm{xx}}^{-1}\right)^{2}-\left(B_{\mathrm{xy}}^{-1}\right)^{2}+\operatorname{det} B^{-1}+B_{\mathrm{xx}}^{-1} \sqrt{N}}{B_{\mathrm{xy}}^{-1}\left(B_{\mathrm{xx}}^{-1}+B_{\mathrm{yy}}^{-1}-\sqrt{N}\right)} .
\end{aligned}
$$

これまでの定常状態に対する数值解析結果では, 磁場 がはたらく場合には, 配向分布は拡散しない( ${ }^{(4)}$ (7). 本 研究での解析結果においても, $B^{-1}$ をみると, 定常状 態が存在することがわかる. 事実, 定常状態について 配向分布をもとめると,

$$
\begin{aligned}
& a=\left\{\frac{N_{1}+\sqrt{N_{1} N_{2}}}{2 M\left(M^{2}-E_{11}^{2}-\alpha \tilde{G}^{2}\right)}\right\}^{1 / 2}, \\
& b=\left\{\frac{N_{1}-\sqrt{N_{1} N_{2}}}{2 M\left(M^{2}-E_{11}^{2}-\alpha \tilde{G}^{2}\right)}\right\}^{1 / 2}, \\
& Z=Z_{1} / Z_{2},
\end{aligned}
$$

となる.ただし，

$$
\begin{aligned}
N_{1}:= & (1-\alpha)^{2} \tilde{G}^{2}+4 M^{2}, \\
N_{2}:= & 4 E_{11}{ }^{2}+(1+\alpha)^{2} \tilde{G}^{2}, \\
Z_{1}:= & \left\{2 E_{11}{ }^{2}+2 E_{11} M+(1+\alpha) \tilde{G}^{2}\right\} \sqrt{N_{1}} \\
& -\left\{2 M^{2}+2 E_{11} M+(1-\alpha) \tilde{G}^{2}\right\} \sqrt{N_{2},} \\
Z_{2}:= & \tilde{G}\left\{(1+\alpha) M-(1-\alpha) E_{11}\right\}\left(\sqrt{N_{1}}-\sqrt{N_{2}}\right),
\end{aligned}
$$

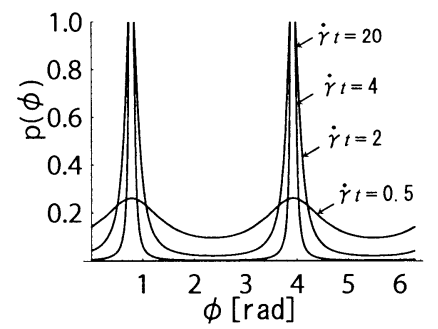

Fig. 3 Polar plots of the probabilities $p(\phi, t)$ for the case $3(\alpha=1)$ under the condition that $E_{11}=$ $0, G_{3}=0$ and $E_{12}=1 . \dot{\gamma} t=0.5,2,4$ and 20 .

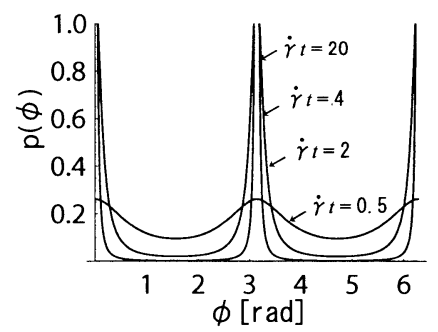

Fig. 4 Polar plots of the probabilities $p(\phi, t)$ for the case 5 under the condition that $E_{11}=1, G_{3}=0$ and $E_{12}=0 . \dot{\gamma} t=0.5,2,4$ and 20 .

とした．また，配向分布のピークの大きさも厳密に求 めることができ,

$\lim _{t \rightarrow \infty} \Psi^{(0)}(0,0, t)=\frac{\xi}{2 \pi}\left\{\frac{\xi^{2}-\left(E_{11}{ }^{2}+E_{12}{ }^{2}-G_{3}{ }^{2}\right) P_{\mathrm{e}}{ }^{2}}{\xi^{2}+G_{3}{ }^{2} P_{\mathrm{e}}^{2}}\right\}^{1 / 2}$,

となる.

図 5 に, 単純せん断流の条件下: $\left(E_{11}, G, E_{12}, \xi, P_{\mathrm{e}}\right)=$ $(0,-1 / 2,1 / 2,70,50)$ および $\dot{\gamma} t=40$ での極座標表示し た場合の配向分布関数を示す. 図 5 から, 角度 $\phi に つ$ いて分布は均質にはならず, 分布にゆがみが生じてい ることがわかる.この分布のゆがみは，定常状態に対 する数值解析の結果 ${ }^{(5)}$ (7) と定性的に合致し, さらに, そのゆがみは, 前節の結果をふまえると, 流れ場に起 因するものであることが分かる. また, 分布のピーク 值についても, この場合,

$$
\lim _{t \rightarrow \infty} \Psi^{(0)}(0,0, t)=\frac{490}{\sqrt{221} \pi},
$$

と具体的に求めることができ，この值も，数值解析に よって示されている結果 ${ }^{(5)}$ とよい精度で合致する.よっ て，以上のことは，本解析結果が妥当であることを示 しており，本解析結果が，粒子の配向分布を定性的に も定量的にもよく評価できるものであることがわかる.

では，上で求めたような定常状態は常に存在するの であろうか? 定常状態の配向分布を決定づける式 (52) から式 (58) をみると, 物理的に意味のある定常状態が 存在するための条件があることがわかる.すなわち, 


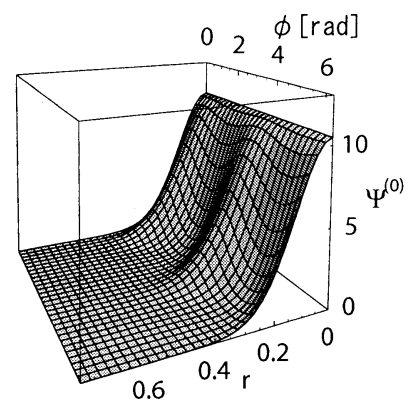

Fig. 5 Polar plot of the orientational distribution function $\Psi^{(0)}(r \cos \phi, r \sin \phi, \dot{\gamma} t)$ under the condition that $E_{11}=0, G_{3}=-1 / 2, E_{12}=1 / 2,(\alpha=0), \xi=$ $70, P_{\mathrm{e}}=50$ and $\dot{\gamma} t=40$.

定常状態を実現するための条件として，

$$
M^{2}-E_{11}^{2}-\alpha \tilde{G}^{2}>0,
$$

を導くことができる，具体的には，条件 (61) から 得られる一葉双曲面（図 6）がなす領域に，さらに， $-1 \leq G_{3} \leq 1$ であることを考慮すると, 磁場と流れ場 の大きさが, 一葉双曲面と $-1 \leq G_{3} \leq 1$ によってつく られる原点を含む領域を満たす場合に，粒子の配向が 維持されることがわかる.このことは，言い換えると， 磁場を印加したとしても，流れ場の大きさによっては， 粒子の配向が維持されない場合が存在することを意味 している. 実際に, 配向が維持されない条件として, 磁場と流れ場がつくる一葉双曲面がなす領域を示すと,

$$
\left(\frac{E_{11}}{\xi / P_{\mathrm{e}}}\right)^{2}+\left(\frac{E_{12}}{\xi / P_{\mathrm{e}}}\right)^{2}-\left(\frac{G_{3}}{\xi / P_{\mathrm{e}}}\right)^{2} \geq 1,
$$

となる.ここで, 条件 (62) を物理的に解釈するため に，一葉双曲面をなす各軸に着目すると，たとえば,

$$
\frac{G_{3}}{\xi / P_{\mathrm{e}}}=\frac{\eta_{\mathrm{s}} Y^{\mathrm{C}}}{\mu_{0} m H} \Omega_{3}, \quad\left(\Omega_{3}:=\dot{\gamma} G_{3}\right),
$$

となることなどから，各軸は，流れ場の各成分と磁場 との割合から成っていることがわかる.したがって， 条件 (62) は, 磁場に対し, 流れ場の大きさと成分がと もに支配的になる場合には，磁場によって粒子の配向 を維持できないことを意味している.

実際に，磁場を印加したにもかかわらず配向分布が拡 散することを確認するために，条件 (62) を満たす例を， 図7 に示す. 図7 では, 図 5 の単純せん断流の条件にお いて $E_{12}$ のみを変更した条件下 : $\left(E_{11}, G_{3}, E_{12}, \xi, P_{\mathrm{e}}\right)=$ $(0,-1 / 2,3 / 2,70,50)$ での配向分布関数を示す. 時間と しては, $\dot{\gamma} t=0.5,4,20$ とした. 図7から, 磁場が印加 されているにもかかわらず， $E_{12}$ の值が $1 / 2$ から $3 / 2$ になるだけで，配向分布が拡散する様子がわかる.

以上のことから, 磁場を印加したとしても必ずしも

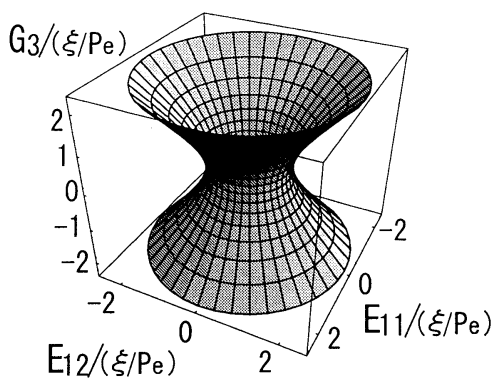

Fig. 6 Hyperboloid of one sheet for the condition.

配向するとは限らず，定常状態を実現するためには， 条件 (61) を満たす必要があることが明らかになった.

最後に，印加した磁場に対する粒子配向の応答性に ついて考察を行う. そのため, 磁場が印加された場合 において，分布のピークの大きさが定常状態に至るま での時間を考える. そこで, 分布のピークの大きさを 決定する量である行列式 $\operatorname{det} B^{-1}$ に着目する. 行列 式 $\operatorname{det} B^{-1}$ の収束にかかわる因子として, 式 (36) 中の,

$$
\exp \left[-2\left(\xi / P_{\mathrm{e}}-\sqrt{E_{11}^{2}+E_{12}{ }^{2}-G_{3}^{2}}\right) \dot{\gamma} t\right],
$$

に注目すると，定常状態に至るまでの時間を評価する 量として,

$$
t_{\mathrm{s}} \sim\left[2 \dot{\gamma}\left(\xi / P_{\mathrm{e}}-\sqrt{E_{11}^{2}+E_{12}{ }^{2}-G_{3}^{2}}\right)\right]^{-1},
$$

を得ることができる.この評価量は, 磁場と流れ場の 大きさによって決定される量であり, 適切な值を得る ためには, 粒子が配向するための条件 (61) を満たして いる必要があることがわかる．このことは，この評価 量が，整合性のある量であることを示しているだけで なく，粒子が配向するための条件をどの程度満たして いるかの指標を意味していることもわかる．実際に， 図 5 と図 7 の場合について算出をすると, 図 5 の場合 では, $\dot{\gamma} t_{\mathrm{s}}=5 / 14$, となり正の值を示すのに対し, 図 7 の場合では, $\dot{\gamma} t_{\mathrm{s}}=-5 /(10 \sqrt{2}-14)$ となり負の值を示 し，不適であることがわかる．また，磁場に対する応 答性を見るために，図 2 を参考にして，配向分布のゆ がみの時間変化に着目すると, 図 5 では, 磁場の影響 により，ゆがみは成長しつづけることはなく，ゆがみ が $\dot{\gamma} t \approx \dot{\gamma} t_{\mathrm{s}}$ に達したときに, 分布が定常状態に至って いることがわかる.

\section{6. 結言}

本研究では，棒状の強磁性微粒子を母液に懸濁した 希釈なコロイド分散系を対象にして，磁場および二次 元流れ場中における粒子の配向分布を理論的に検討し た. 特に，流れ場がなす平面に垂值な方向に磁場が支 


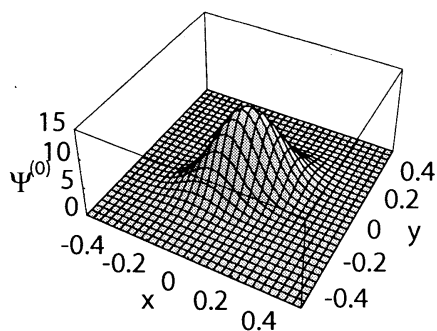

(a) $\dot{\gamma} t=0.5$

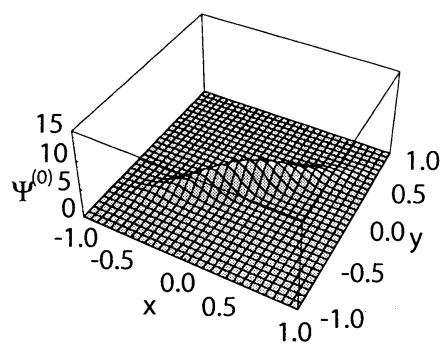

(b) $\dot{\gamma} t=4$

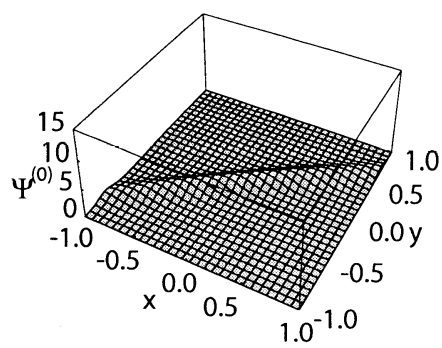

(c) $\dot{\gamma} t=20$

Fig. 7 Orientational distribution function $\Psi^{(0)}$ for $E_{11}=0, G_{3}=-1 / 2, E_{12}=3 / 2, \xi=70$ and $P_{\mathrm{e}}=50$. (a) $\dot{\gamma} t=0.5$, (b) $\dot{\gamma} t=4$, (c) $\dot{\gamma} t=20$.

配的である場合に着目し，磁場が任意の方向に与えら れた場合に対して，配向分布関数が満たす支配方程式 に, 適切な変数変換と摂動展開を与えることにより, 時間を含む基礎方程式を導出する方法を示した.この 方法によって得た基礎方程式に対し，可解条件から得 られる関数がつくる行列の逆行列に着目することによ り, 厳密解を導いた. 実際に, この厳密解を用いて, 配向分布関数を用いた統計平均量を算出した.さらに, 解析的に, 配向分布の特徵と時間挙動についての定量 的評価を行った. 流れ場が配向分布に及ぼす影響とし て，流れ場がもたらす，配向分布のゆがみの特徴を明 らかにし，磁場が働かない場合は配向分布は必ず拡散 してしまうことを示した。 しかし，たとえ，磁場を印 加したとしても必ずしも配向分布の定常状態を実現で きるとは限らないことも解析的に示し，実際に定常状 態を実現するための条件が，磁場と流れ場の大きさか
らなる一葉双曲面がなす領域によって与えられること を示した．最後に，印加した磁場に対する配向の応答 性として，定常状態に収束する速さに関する評価量を 導出した。

本研究の一部は, 文部科学省科学研究費の援助を受 けてなされたことを記し，感謝の意を表す。

\section{文献}

(1) For example; Bullough, W. A. ed., Electoro-Rheological Fluids, Magneto-Rheological Suspensions and Associated Technology, (1996), World Scientific, and references therein.

(2) Rosensweig, R.E., Ferrohydorodynamics, (1985), Cambridge University Press.

(3) Aoshima, M. et al., Two-Dimensional Monte Carlo Simulations of a Colloidal Dispersion Composed of Polydisperse Ferromagnetic Particles in an Applied Magnetic Field, Kagaku Kogaku Ronbunshu, Vol.30, (2004), pp.771-777.

(4) Satoh, A., Rheological Properties and Orientational Distributions of Dilute Ferromagnetic Spherocylinder Particle Dispersions, Journal of Colloid and Interface Science, Vol.234, (2001), pp.425-433.

(5) Aoshima, M. et al., Rheological Properties and Orientational Distributions of Dilute Ferromagnetic Spherocylinder Particle Dispersions (PartII. Analysis for the Two Typical Magnetic Field Directions), Journal of Colloid and Interface Science, Vol.253, (2002), pp.455-464.

(6) Satoh, A., Rheological Properties and Particle Behaviors of a Nondilute Colloidal Dispersion Composed of Ferromagnetic Spherocylinder Particles subjected to a Simple Shear Flow (Analysis by Means of Mean-Field Approximation), Journal of Colloid and Interface Science, Vol.262, (2003), pp.263-273.

(7) Watanabe, T. et al., Rheological Properties and Particle Behaviors of a Nondilute Colloidal Dispersion composed of Ferromagnetic Spherocylinder Particles subjected to a Simple Shear Flow (Analysis by Means of Mean-field Approximation for the Two Typical External Magnetic Field Directions), Journal of Colloid and Interface Science, Vol.302, (2006), pp.347-355.

(8) Kim, S. \& Lawrence, C., Similarity solutions for the orientation distribution function and rheological properties of suspensions of axisymmetric particles with external couples, Journal of Non-Newtonian Fluid Mechanics, Vol.24, (1987), pp.297-310.

(9) Itoh, H. and Sugimoto, T., Systematic control of size, shape, structure, and magnetic properties of uniform magnetite and maghemite particles, Journal of Colloid and Interface Science, Vol.265, (2003), pp.283-295.

(10) Brenner, H., Rheology of a Dilute Suspension of Axisymmetric Brownian Particles, International Journal of Multiphase Flow, Vol.1, (1974), pp.195-341.

(11) Kim, S. and Karrila, S. J., Microhydrodynamics, (2005), pp.61-65, Dover Publications, Inc.

(12) Foister, R. T. \& Van De Ven,T.G.M., Diffusion of Brownian particles in shear flows, Journal of Fluid Mechanics, Vol.96, (1980), pp.105-132. 